\title{
C) HitșTórica
}

\section{Construção do mito de herói nacional: Eduardo Gomes e sua atuação no Movimento Tenentista}

\author{
Construction of the myth of national hero: Eduardo Gomes and his performance in the \\ Tenentista Movement
}

Flavia Salles Ferro"

Resumo: O artigo compreende a construção da imagem de herói nacional em torno de Eduardo Gomes. A hipótese é que o mito legitimou sua candidatura ao cargo de presidente da República pelo partido União Democrática Nacional em 1945 e 1950. A elaboração da imagem baseou-se em memórias de sua participação no Levante do Forte de Copacabana e na Revolta Tenentista de 1924, ou seja, em sua atuação como revolucionário durante a Primeira República. Contudo, cabe questionar: quem construiu o mito? A que a legenda de herói nacional conveio? De que maneira a sociedade respondeu à construção do mito? Este estudo, através da análise de imprensa e correspondências, responderá essas indagações.

Palavras-chave: Eduardo Gomes, herói, eleição presidencial de 1945.

Abstract: The article comprises the image construction of national hero Eduardo Gomes. The hypothesis is that the myth legitimized his Republic presidential candidacy by the União Democrática Nacional party in 1945 and 1950. The elaboration of the image was based on memories of his participation in the Levante do Forte de Copacabana and the Revolta Tenentista de 1924, that is, in his determination as a revolutionary during the First Republic. However, it must be asked: who built the myth? What did the legend of a national hero do? How has society responded to the construction of the myth? This study, through the press and letters analysis, will answer these questions.

Keywords: Eduardo Gomes, hero, presidential election of 1945.

"Doutoranda no Programa de Pós-Graduação em História da Universidade Federal de Juiz de Fora (UFJF), bolsista CAPES. 


\section{Eduardo Gomes: breve biografia}

Eduardo Gomes foi personagem de intensa participação política no Brasil. Nasceu em Petrópolis (RJ) em I896. Filho de Jenny e Luís Gomes. Sua família detinha posses e eram herdeiros de nomes relacionados à política. Em 1916, ingressou na Escola Militar do Realengo, no Rio de Janeiro. Finalizado o curso em dezembro de I9I8, foi declarado aspirante-a-oficial das armas de artilharia. Neste mesmo ano matriculou-se no Curso Especial de Artilharia, concluindo em 1919. Em dezembro deste, passou a segundo-tenente, sendo transferido para o $9^{\circ}$ Regimento de Artilharia, em Curitiba. Em janeiro de I92I foi promovido à primeiro-tenente.

Foi sob a patente de primeiro-tenente que Eduardo Gomes participou do Levante do Forte de Copacabana, ocorrido no Rio de Janeiro, em julho de 1922. Atuou também em I924 na Revolta Tenentista em São Paulo. Após o movimento, foi preso quando viajava ao Paraná na intenção de se juntar a Coluna Miguel Costa-Luís Carlos Prestes. Passou os anos seguintes ora encarcerado, ora refugiado. Anistiado em maio de 1930, Eduardo Gomes participou da Aliança Liberal, atuando na Revolução de 1930 que colocou fim à Primeira República.

Após o movimento revolucionário de 1930, Eduardo Gomes dedicou-se à carreira militar. Participou da criação e dirigiu, em I93I, o Correio Aéreo Militar. É Em I932, combateu os revoltosos paulistas, contribuindo nos entendimentos promovidos pelo Governo Provisório e o estado de São Paulo. Terminado o movimento revolucionário de 1932, Eduardo Gomes retomou suas atividades no Correio Aéreo Militar. Atuou como comandante do I $^{\mathrm{o}}$ Regimento de Aviação e foi promovido a tenente-coronel em 1934. Participou, sob essa patente, junto às forças legalistas contra o levante organizado pelo Partido Comunista do Brasil (PCB), em 1935.

Instaurado o Estado Novo em 1937, Gomes pediu exoneração do comando do Io Regimento de Aviação. Em I94I, após a criação do Ministério da Aeronáutica, foi promovido a brigadeiro e, em seguida, nomeado comandante das Zonas Aéreas I e II, com sedes em Belém e em Recife. Em Pernambuco, atuou na construção de bases aéreas com investimentos financeiros norte-americanos. O político teve papel de destaque nas relações

\footnotetext{
I O Correio Aéreo Nacional tem como objetivo integrar as diversas regiões do país, permitir a ação governamental em comunidades de difícil acesso e desenvolver a aviação.
} 
entre o governo brasileiro e os Estados Unidos durante a Segunda Guerra Mundial. Em setembro de 1944 foi elevado a major-brigadeiro do ar.

Eduardo Gomes disputou a eleição presidencial de 1945 pela legenda da União Democrática Nacional. Foi derrotado. No entanto, isso não impediu que fosse novamente escolhido pelo partido para as eleições de 1950, em que novamente não conquistou o cargo de presidente da República. Durante a primeira experiência democrática, Gomes foi opositor a Vargas e seu legado trabalhista. Foi convidado por Getúlio Vargas para ser ministro da Aeronáutica, mas recusou. No governo de Café Filho (1954-1955) assumiu esta pasta. Em setembro de 1960, Eduardo Gomes foi promovido a marechal-do-ar. Em 1964, foi um dos principais articuladores na conspiração para o golpe civil-militar que depôs o presidente João Goulart. Em 1965 retomou o cargo de ministro da Aeronáutica, permanecendo até março de 1967. Eduardo Gomes faleceu em I98I.

\section{Movimento Tenentista: Eduardo Gomes e a memória heroica}

Eduardo Gomes tornou-se figura pública ao participar do Levante do Forte de Copacabana, em 1922. A revolta iniciou as manifestações tenentistas ocorridas durante a Primeira República. É possível apreender o Movimento Tenentista em duas fases. A primeira abrange as revoltas de 1922 e I924. A segunda fase tem seu proêmio em 1924, mas sua principal articulação ocorre na Coluna Miguel Costa - Luís Carlos Prestes. É importante destacar, contudo, que o tenentismo foi um processo de construção de consciência e identidade coletiva. Assim sendo, não se ignora as relações entre os eventos, bem como a importância da Revolta de $\mathbf{9 2 4}$ para organizar e definir os planos dos militares revoltosos que marcharam o Brasil entre os anos 1925 e 1927.

Esta divisão é pensada baseando-se nos interesses que motivaram os revoltosos. $\mathrm{O}$ movimento tenentista inicia-se em contexto de insatisfação do exército diante do tratamento que eles haviam recebendo do governo de Epitácio Pessoa, mas principalmente, devido a inconformidade com a vitória de Artur Bernardes para presidente da República, que foi intensificada com o episódio das cartas falsas. A revolta ocorreu em reação à prisão de Hermes da Fonseca. Não havia interesse em mudar a estrutura política e social brasileira. O interesse era impedir o governo de Artur Bernardes.

O levante de 1924 expressou o amadurecimento dos interesses coletivos. Houve pauta de mudanças sociais e críticas às estruturas políticas. Contudo, será demonstrado ao 
longo do texto que, assim como em 1922, a revolta paulista foi motivada pela defesa do Exército e crítica ao governo de Artur Bernardes.

Em 9 de outubro de I92I, ano de eleição presidencial, o Correio da Manhã publicou artigo com título "Injurioso e Ultrajante". Nele, havia a transcrição de suposta carta escrita em 3 de junho daquele ano, de autoria de Bernardes, então presidente do estado de Minas Gerais, direcionada a Raul Soares. Na correspondência ele se refere ao marechal Hermes da Fonseca como "sargentão sem compostura". Sobre o Exército, sugeria que Epitácio Pessoa, presidente da República, reprimisse a indisciplina dos militares "punindo severamente esses ousados, prendendo os que saíram da disciplina e removendo para bem longe esses generais anarquizadores. Se o Epitácio, com medo, não atender, use de diplomacia, que depois do meu reconhecimento ajustaremos contas".2

No dia seguinte, outra carta foi publicada pelo jornal. Nesta, escrita em 6 de junho de I92I, Bernardes discordava de outra prorrogação da Convenção, pois tinha apreensão da chegada de Nilo Peçanha. Acreditava que seu opositor seria capaz de tudo. Pediu a Raul Soares que removesse toda dificuldade, sem se preocupar com despesas.

O Clube Militar no mesmo dia de publicação da carta, reuniu os sócios para tratar do assunto, sob a presidência de Hermes. À mesa foi encaminhada uma moção assinada pelos 80 sócios presentes declarando a incompatibilidade entre eles e Artur Bernardes e evidenciou a não aceitação de Artur Bernardes como presidente da República:

\begin{abstract}
À nação - o Clube Militar - órgão das classes armadas - julga de seu dever declarar que o público conceito emitido pelo Sr. Artur Bernardes, na sua carta de 3 de junho último, colocou o Exército na contingência de reagir imediatamente. Porque, ou S. Excia. tem razão em nos qualificar de canalha venal, ou inutilmente ultrajou o Exército. Na primeira hipótese, o Exército deve ser dissolvido pois a defesa da Nação não pode estar confiada a [...] e canalhas; na segunda, S. Exa. Criou absoluta incompatibilidade entre a sua pessoa e o Exército. Existe, pois, um dilema, com solução única: ou a nossa dissolução, ou o Exército não aceita que S. Exa. Seja o Presidente da República.3
\end{abstract}

Artur Bernardes negou a autoria das cartas. O Clube Militar instaurou comissão verificadora para comprovar sua autenticidade. Antônio Augusto de Serpa Pinto foi

\footnotetext{
2 "Injurioso e Ultrajante". Correio da Manhã, edição 8255, 9 de outubro de I92I, p. 2

3 "Reunião do Club Militar". Correio da Manhã, II de outubro de I92I, edição 8257, p. 3.
} 
responsável por avaliar a veracidade. Em contrapartida, os assessores de Bernardes encarregaram os peritos Simões Correia e general Alexandre Barbosa Lima. Simões Correia defendeu em seu laudo falsificação por decalque. Já a perícia do Clube Militar concluiu autenticidade das cartas.

Os militares, que estavam inseguros com o tratamento do governo com eles, diante da divulgação das cartas supostamente escritas por Bernardes e autenticadas pela comissão verificadora do Clube Militar, demonstraram insatisfação com a política governada por civis.

Em 3 de fevereiro de 1922, Oldemar Lacerda confessou aos diretores do Clube Militar que falsificou as cartas. Eles, entretanto, não divulgaram. Ainda que, com a confissão de Oldemar Lacerda e a comprovação por peritos de que o documento não era verdadeiro, a imprensa opositora de Bernardes continuou descrevendo o personagem como inimigo do Exército.

O Correio da Manhã e Jornal do Brasil se negaram a concordar que as cartas foram forjadas. Em Io de junho de 1922, o Correio da Manhã publicou artigo problematizando o caso das cartas. Afirmou que o documento, para além da perícia dirigida pelo Exército e Marinha, recebeu laudo comprobatório de Edmond Locard, professor europeu. Segundo a notícia, o bernardismo se apegou à possibilidade de decalque da carta, que só poderia ser descoberto por processo microfotográfico. Locard, então, “[...] depois da aplicação da microfotografia, aventada pelo sr. Simões Correa, não só repeliu a hipótese do decalque, como ainda depois de outros exames declarou, com a autoridade e a probidade do seu nome, que a carta de Bernardes é "autêntica"."4

O resultado da eleição presidencial de 1922 garantiu a vitória ao candidato oficial, como era esperado. A oposição, então, pediu a abertura de "Tribunal de Honra", com vista a substituir o Congresso Nacional na função de reconhecer o candidato eleito. No entanto, tal pedido foi recusado pelo governo.

Em fins de maio de 1922, ocorreu eleições para governador do estado de Pernambuco. Pleitearam os candidatos Carlos de Lima Castro, então presidente de Recife, representante da chapa oficial, e José Henrique Carneiro da Cunha, indicado pela oposição. A vitória, como era rotineiro na Primeira República, foi do candidato que tinha apoio do governo federal. Após a eleição, iniciaram conflitos em Pernambuco, devido aos 5 dois candidatos terem se declarado vitoriosos. Sob justificativa de manter a ordem, forças

\footnotetext{
4 “O reconhecimento".Correio da Manhã, edição 8497, Io de junho de i922, p. 2.

${ }^{5}$ Posteriormente, grupos políticos de Pernambuco entraram em acordo e escolheram para governar o estado,
} 
federais ocuparam Recife por três dias. A população descontente, mobilizadas por Joaquim Pimenta, líder operário, ocuparam prédios, em resistência às forças legalistas.

Em fins de junho de 1922, o marechal Hermes da Fonseca, presidente do Clube Militar, foi procurado, através de correspondência, por oficiais que serviam em Pernambuco. Eles estavam insatisfeitos com a intervenção federal naquele estado e com o papel desempenhado pelo Exército nesse episódio. Em resposta, Hermes da Fonseca enviou telegrama a Jayme Pessoa, comandante da Região Militar de Pernambuco:

[...] venho fraternalmente lembrar-vos mediteis termos arts. 6 e I4 Constituição, pra isentardes vosso nome e da nobre classe a que pertencemos da maldição dos nossos patrícios. $\mathrm{O}$ apelo que ora dirijo ao nosso ilustre consocio é para satisfazer instantes pedidos de camaradas nossos daí, no sentido de apoia-los nessa critica emergência, em que se procura desviar força armada de seu destino. Confiante vosso patriotismo e zelo pela perpetuidade do amor do Exército ao povo de nossa terra. Não esqueçais que as situações políticas passam e o Exército fica. 6

O ministro da Guerra, João Pandiá Calógeras, procurou Hermes da Fonseca para que ele confirmasse se era realmente o autor da correspondência, o que ele admitiu, sem hesitar. Por assim ser, Pandiá Calógeras mandou prender, por 24 horas, no dia 2 de julho de 1922, o marechal Hermes da Fonseca. Como justificativa para repreende-lo, Calógeras elencou que o militar, pelo ato de estar associado, não se exonera dos deveres de subordinação e de disciplinas previstos na legislação que rege as forças armadas; colocou em dúvida a palavra de seu superior hierárquico - presidente da República; declarou "solenes e inequívocas" afirmações de que Epitácio Pessoa estava intervindo em Pernambuco e expandindo ordens ilegais; entre outros argumentos.7

No mesmo dia da prisão do marechal Hermes da Fonseca, a diretoria do Clube Militar publicou nota assumindo responsabilidade pelo telegrama enviado a Jayme Pessoa. Informaram que a atitude do presidente do Clube resultou de deliberação, unanime, tomada em sessão realizada a 28 de junho.8 Em resposta, Pandiá Calógeras deu ordens para fechar o Clube Militar por seis meses.

Os militares reagiram à prisão do marechal Hermes da Fonseca. Na madrugada do

\footnotetext{
entre os anos I922 e I926, o juiz federal Sérgio Loreto.

6 "Tópicos e Notícias". Correio da Manhã, 30 de junho de I922, edição 8517, p. 5.

${ }^{7}$ Jornal do Brasil, edição I57, 2 de julho de I922, p. 5; O Paiz, edição I57, 2 de julho de I922, p.5.

"A intervenção federal em Pernambuco volta a preocupar intensamente a opinião nacional”. Correio da Manhã, edição 85I9, 2 de julho de I922, p.I.
} 
dia 5 de julho, dias após a repressão, os tenentes organizaram movimento de oposição ao governo federal. Ocorreu, então, o Levante do Forte de Copacabana. Sob liderança do capitão Euclides Hermes da Fonseca, filho do marechal Hermes da Fonseca, os tenentes tomaram o Forte de Copacabana. Outras guarnições participaram do movimento: Vila Militar, Forte do Vigia, Escola Militar do Realengo e I ${ }^{\circ}$ Batalhão de Engenharia. Em Niterói, membros da Marinha e do Exército se rebelaram. Em Mato Grosso, sob comando do general Clodoaldo da Fonseca, tio de Hermes da Fonseca, a I ${ }^{a}$ Circunscrição Militar também participou da revolta. Diante da liderança da revolta ter sido realizada por familiares de Hermes da Fonseca, fica evidente que o estopim para que ocorresse o movimento foi sua prisão.

O governo federal, através do Exército, dominou facilmente o Levante, impedindo a continuidade da revolta. Inicialmente, Pandiá Calógeras trabalhou no intuito de conseguir rendição dos rebeldes. Contudo, eles desejavam negociar, o que, firmemente, o governo recusou. O movimento encerrou no dia 6 de julho, quando os revoltosos, diante da impossibilidade de vitória, marcharam na avenida Atlântica, em Copacabana, em direção às forças legalistas. Entre os participantes, estavam os tenentes: Newton Prado, Eduardo Gomes, Siqueira Campos, Mário Carpenter e o civil Otávio Correia. Eduardo Gomes foi quem deu a ideia dos revoltosos marcharem de encontro às forças legalistas. Ele saiu do conflito com fratura exposta em seu fêmur esquerdo.

Os revoltosos foram julgados pelo artigo I07 do Código Penal: “Tentar, diretamente e por fatos, mudar por meios violentos a Constituição política da República, ou a forma de governo estabelecida. Pena: banimento, aos cabeças, e aos co-réos a reclusão por cinco a dez anos". 9

Eduardo Gomes não foi visto como "cabeça" do movimento e sim co-réo, uma vez que sua punição foi o cárcere, ao invés do exílio como foi o caso de Siqueira Campos. Em 1923, devido a habeas corpus, Eduardo Gomes foi solto. Dias antes de sair seu decreto de prisão ele fugiu para Mato Grosso, onde ficou refugiado até a Revolta de I924.

Em 5 de julho de 1924 um novo levante organizado pela baixa oficialidade do Exército eclodiu. A data não foi coincidência, ela homenageou o primeiro conflito de oposição ao governo federal organizado pelos tenentes. A conspiração do levante teve como idealizadores: Henrique Ricardo Hall, Vítor César da Cunha Cruz, Miguel Costa, João Francisco Ferreira de Souza, Joaquim Távora, Eduardo Gomes, Arlindo de Oliveira, Nilton Estillac Leal, Thales Marcondes, Osmar Soares Dutra, Paulo Weber Vieira da Rosa,

\footnotetext{
9 "Os acontecimentos de julho do ano passado". Correio da Manhã, 27 de dezembro de I923, edição 9058, p. 3.
} 
Diogo Moreira de Figueiredo e Emílio Miranda. Foi liderada pelo general Isidoro Dias Lopes. (SILVA, I97I, p. 366).

Eduardo Gomes atuou sublevando o $4^{\circ}$ Batalhão de Caçadores e os $\mathrm{I}^{\mathrm{o}}, 2^{\circ}$ e $4^{\mathrm{o}}$ Batalhões de Infantaria. Foi comandante da aviação dos revoltosos. Nesta função foi responsável pela missão de levar 30 mil manifestos revolucionários aos quartéis da Vila Militar do Rio de Janeiro e, ainda, uma bomba, cujo destinatário era o Palácio do Catete. Contudo, foi necessário pouso forçado do avião na região de Cunha, interior de São Paulo, a qual era dominada pelas forças legalistas. Para não ser preso, Eduardo Gomes fingiu ser oficial a mando do governo. Conseguiu fugir para Aparecida, também no estado de São Paulo, e, então, para o Rio de Janeiro, onde se refugiou.

Os objetivos da Revolta Tenentista de 1924 foram conhecidos como reformar a Constituição, instaurar o voto secreto e obrigatório, revogar a lei de imprensa, preservar a autonomia do poder judiciário e garantir o ensino primário gratuito e obrigatório. Contudo, dias após a eclosão do movimento, os revoltosos publicaram nota no jornal $O$ Estado de São Paulo informando as motivações da revolta:

[...] o Exército Nacional não pode e não pôde, nunca, aceitar o governo do dr. Artur Bernardes, no que diz respeito particularmente a sua pessoa. Não obstante os fatos conhecidos, persistem de pé as gravíssimas ofensas por ele dirigidas ao Exército. [...] O Exército não tem ambições e não quer postos. [...] Nesse sentido, os chefes do movimento revolucionário querem dar o exemplo que empreste autoridade à sua crítica aos republicanos que, até agora, ocuparam os altos postos da administração do país e que, com raras exceções, não souberam servi-lo nos seus interesses gerais. ${ }^{\text {II }}$

É possível compreender que os revoltosos se percebiam como garantidores da honra da Nação e da Constituição que vinha sendo infringida por governantes civis, especialmente Artur Bernardes, o qual, nunca pôde ser aceito pelo Exército, uma vez que desde sua candidatura a presidente da República, ofendeu os militares através do episódio das cartas. Posteriormente, como chefe do governo federal, puniu os militares com prisões e transferências, e governou em estado de sítio. Nota-se, ainda na publicação do manifesto dos revoltosos, que não há definição de programa de medidas, como depois se definiu e

\footnotetext{
${ }^{\text {Io }}$ Carta de Isidoro Dias Lopes para Azevedo Lima, Foz do Iguaçu, 27 de fevereiro de I925. Arquivo Público do Estado de São Paulo, acervo "Cartas da Revolução de 24".

11 "Um comunicado dos chefes do movimento". O Estado de São Paulo, Io de julho de 1924, edição I6596, p. I.
} 
ficou conhecido o movimento.

Pode-se pensar, portanto, que, no imediato da revolta, os tenentes não possuíam plataforma de reivindicações sociais e mudanças estruturais na política, apenas mostravam descontentamento com a política e com o tratamento que o Exército recebia do governo federal. Contudo, o movimento inaugura o início de um projeto político, em que há a defesa da deposição do presidente da República, moralização do sistema político, voto secreto e ensino público obrigatório.

José Augusto Drummond (1986) analisa que o contexto de crise política não foi explicação unívoca para os tenentes se rebelarem. Segundo o historiador, o que motivou os revoltosos a novamente se manifestarem contra o governo de Arthur Bernardes foi a ameaça de expulsão do Exército aos participantes da Revolta Tenentista de 1924 e a inconformidade de serem julgados pelo artigo I07 do Código Penal. Este trabalho corrobora com as análises feitas por Drummond.

Após o movimento, os revoltosos presos foram julgados novamente pelo artigo IO7 do Código Penal. Nos autos de suas defesas há:

O intuito da revolta de 22 fora o de impedir a posse de Bernardes, em consequência dos agravos por ele feitos ao Exército Nacional, nas cartas que lhe foram atribuídas, provocando fortíssima exaltação de ânimo. Depois de sua posse o presidente, então reconhecido, manteve a maior parte do país em estado de sítio permanente, serviu-se da força para depor o governo legalmente constituído no Estado do Rio de Janeiro, praticando numerosos atentados antidemocráticos que constituíram os principais germes da revolução de 24. Com esses fundamentos pedimos absolvição, porque o movimento de 5 de julho de 24 foi uma resistência coletiva a atos arbitrários do Executivo Federal, a atoa violadores da Constituição a que devem igualmente obediência e respeito governantes e governados. (SILVA, I97I, p. 406).

É importante considerar que a declaração de defesa é um ato de evitar a prisão aos co-réus e exílio aos cabeças da revolta. Contudo, é possível observar o discurso de crítica à Bernardes devido às suas ações contra o Exército e compreender a percepção dos militares como protetores da Nação, aqueles que resistiram à arbitragens e lutaram para garantir a Constituição.

Eduardo Gomes ao participar das revoltas tenentistas de 1922 e 1924 atuou como 
membro do Exército, grupo este com o qual ele compartilhava identidade, pensamento político, interesses e horizonte de expectativa. Ele não participou da Coluna Miguel CostaLuís Carlos Prestes. Foi preso antes de se juntar ao movimento. Assim sendo, o personagem envolveu-se apenas com o primeiro momento do Movimento Tenentista. Suas ações, portanto, estão vinculadas à corporação dos militares revoltosos. São interesses coletivos que permeiam a defesa do Exército e a ideologia deste como garantidor da ordem que vinha sendo desmantelada pelos civis que governavam o país.

\section{Eleição presidencial de I945: construção do herói}

Em fins de 1944, antes de Getúlio Vargas chamar eleições presidenciais, Eduardo Gomes foi procurado por Virgílio de Mello Franco, Juracy Magalhães, Ari Parreiras, Prado Kelly e Juarez Távora para iniciarem a preparação para a fundação de partido nacional opositor ao governo federal - a União Democrática Nacional. O major-brigadeiro Eduardo Gomes foi escolhido para ser candidato à presidência da República. A escolha da sucessão presidencial foi por, como analisou Maria Victoria Benevides, ele ter alto posto militar, legenda de herói e tradição de lutas democráticas, aliadas a "nome limpo". (BENEVIDES, I98I, p.42)

Eduardo Gomes, como foi narrado acima, atuou como tenente revolucionário na Primeira República. Os tenentes foram aclamados heróis nacionais devido à importância que tiveram para por fim ao governo "corrompido", "oligárquico", "fraudulento", como assim era chamada a "República Velha" pelos que construiriam o novo governo. Os militares conhecidos no movimento tenentista, neste contexto, não representaram apenas a dimensão militar da Revolução de I930: o tenentismo abrangia os ideais revolucionários característicos dos que participaram da Aliança Liberal. Mário Lanna Júnior escreveu: “É, antes de tudo, um movimento revolucionário. Como salvador da pátria, denunciava a desmoralização dos costumes políticos pelas oligarquias, que deveriam ser banidas da política, por corromperem as instituições, em específico as forças armadas". (LANNA JÚNIOR, 20IO, p. 347).

A partir da participação política de Eduardo Gomes como tenentista e, portanto, como elucidou Lanna Júnior, participante do movimento revolucionário que foi tido como salvador da pátria, construiu-se em torno da figura pública do personagem a imagem de herói nacional. 
A legenda de herói permaneceu e fora intensificada nos anos que se seguiram. José Murilo de Carvalho analisa que "heróis são símbolos poderosos, encarnações de ideias e aspirações, pontos de referência, fulcros de identificação coletiva; são, por isso, instrumentos eficazes para atingir a cabeça e o coração dos cidadãos a serviço da legitimação de regimes políticos" (CARVALHO, 1990, p. 55). O mito tem em sua elaboração a intenção de fornecer esperança e conforto diante de ameaças.

A construção de símbolos nacionalistas está sempre vinculada à memória. É preciso resgatar sua identidade, valorizar seus feitos, recorrer, portanto, ao passado para validar a opinião no presente. No caso da construção de heróis nacionais, Carvalho analisa que é um instrumento eficaz para legitimar regimes políticos. Sendo assim, é possível relacionar que a construção da legenda de herói em torno de Eduardo Gomes teve como base vivencias de grupo que identificava na Primeira República a consagração dos males do Brasil e via em Gomes a importância para sua ruptura através de sua participação no movimento tenentista. Posteriormente, sua legenda foi recuperada por Virgílio de Mello Franco, Juracy Magalhães, Ary Parreiras, Juarez Távora e Prado Kelly ao pensar no personagem heroico para novamente salvar o país, agora de uma ditadura. Construiu, portanto, em torno de Gomes uma memória histórica.

Memórias são experiências coletivas. Por assim ser, a retomada da legenda de herói nacional em torno da figura de Eduardo Gomes foi reavivada com lembranças que eram compartilhadas por grupo que tinham noções em comum e as quais permaneciam fazendo sentido no tempo presente, neste caso, no contexto da crise do Estado Novo. A finalidade, portanto, em construir o mito de herói nacional sobre Eduardo Gomes para concorrer à presidência da República pela UDN fez parte de estratégia de atingir as mentes e corações, bem como legitimar a defesa do partido para o fim do legado varguista.

Em 28 de fevereiro foi promulgada a Lei Constitucional $n^{\circ}$, que fixou o prazo de noventa dias para que fossem marcadas as eleições e determinou a elaboração de lei eleitoral. Entre os partidos fundados estavam o Partido Social Democrático (PSD), o Partido Trabalhista Brasileiro (PTB) e a União Democrática Nacional (UDN) que dominaram o jogo político no Brasil durante os anos da experiência democrática (1945I964).

A União Democrática Nacional foi oficialmente fundada em sete de abril de 1945. Ela foi criada como movimento, frente de oposição, reunindo de antigos partidos estaduais e aliança política entre novos parceiros. A frente de oposição agregou as mais variadas tendências políticas e raízes históricas. Personagens como Arthur Bernardes - político que 
simbolizava a Primeira República -, Ademar de Barros - ex-interventor de São Paulo, e que não tinha a confiança das elites paulistas - e Osvaldo Aranha - amigo e aliado de Getúlio Vargas, ex-ministro das Relações Exteriores.

Diante da variedade dos quadros da UDN, que incluía políticos dominantes do período anterior a Revolução de 1930, o partido foi considerado pela população como desejoso de reconquistar o poder que perdeu desde a Revolução. Assim, a UDN era vista como pretensiosa a voltar ao passado - ao tempo do voto de cabresto, das longas jornadas de trabalho, dos péssimos salários. Ela não vinha, pois, salvar a população de um governo autoritário, fascista, manipulador, violento - como a UDN acusava o regime de Vargas. $\mathrm{O}$ partido, com a vitória, poderia levar o Brasil, e os trabalhadores, às condições de vida do passado - do anterior ao governo Vargas.

A impressão elitista que se tinha sobre a União Democrática Nacional era corroborada com os participantes dos comícios. Segundo relato de Hermes Lima sobre comício realizado no Pacaembu, em São Paulo, no dia I6 de junho de I945, quando o brigadeiro Eduardo Gomes apresentou a plataforma da UDN:

ao entrar no estádio fiquei aterrado. Repletas as sociais de um público seleto, elegante mesmo, em que se destacava numeroso concurso de senhoras, de chapéu e calçando luvas, mas as gerais vazias. Era um espetáculo politicamente confrangedor, a enorme praça de esportes, metade morta, metade bem composta, até nas palmas com que saudou o candidato e lhe aplaudiu o discurso. (BENEVIDES, Op. cit., p.45).

Fica evidenciado, dessa forma, as disparidades de memórias e opiniões sobre Eduardo Gomes. Se, por um lado, fez parte da estratégia do partido ter o político como candidato a presidente da República por ser conhecido herói nacional devido à participação no movimento tenentista e, dessa forma, ter contribuído para pôr fim à República Oligárquica. Ao mesmo passo, agremiava em torno da UDN políticos beneficiados pela Primeira República.

Michael Pollak afirma que memória é "um fator extremamente importante do sentimento de continuidade e de coerência de uma pessoa ou de um grupo em sua reconstrução de si." (POLLAK, 1992, p. 5). Por assim ser, memória e identidade estão relacionadas com o sentimento de pertencimento do indivíduo a um grupo social. Pollak analisa também que memória de grupo muitas vezes constitui-se através de batalhas, disputas sobre qual versão predominará de um mesmo episódio. A memória e o 
esquecimento são partes da mesma moeda. É necessário escolhas sobre o que lembrar e o que esquecer.

Observa-se que ocorreu batalha de memórias em torno da figura de Gomes. O personagem era aclamado pela UDN como solução para a ditadura varguista. Mas os trabalhadores queriam a saída de Vargas? Ao construírem a legenda de Gomes como membro do movimento tenentista e da Aliança Liberal, procurava-se destacar seu envolvimento para pôr fim a Primeira República. Contudo, é necessário perceber que a Revolução de 1930 encerrou a República Oligárquica e colocou Vargas no poder. Assim sendo, se por um lado, Gomes fora aclamado herói nacional por isso, por outro, no contexto de 1945, ele se consagrava opositor ao personagem político que centralizou o governo, criou leis trabalhistas, propiciou maior participação social na política, ou seja, aquele que não apenas contribuiu para o fim da Primeira República, como deu continuidade ao processo de ruptura ao domínio das oligarquias.

É importante ressaltar que fez parte da estratégia de governo de Getúlio Vargas construir lugares de memórias que enaltecessem sua figura. Pierre Nora analisa:

Os lugares de memória nascem e vivem do sentimento que não há memória espontânea, que é preciso criar arquivos, que é preciso manter aniversários, organizar celebrações, pronunciar elogios fúnebres, notariar atas, porque essas operações não são naturais. [...] Sem vigilância comemorativa, a história depressa as varreria. São bastiões sobre os quais se escora. Mas se o que eles defendem não estivesse ameaçado, não se teria, tampouco, a necessidade de constituí-los. (NORA, I993, p. I3).

Vargas construiu diversos lugares de memórias. A programação diária Hora do Brasil na rádio, em que Alexandre Marcondes Filho, ministro do Trabalho, Indústria e Comércio, falava semanalmente enfocando a legislação social produzida, regulamentada e reformada a partir de 1930 foi um lugar de memória construído no governo Vargas. Ângela de Castro Gomes descreve: "a história das leis sociais, seu conteúdo, seus pontos polêmicos, tudo isto era tratado pelo ministro em tom pedagógico e até mesmo paternal". (GOMES, I988, p. 233). As celebrações do Dia do Trabalhador (Primeiro de Maio), aniversário do Presidente (I9 de abril), aniversário do Estado Novo (Io de novembro), fizeram parte da estratégia política de Vargas de propagandear seu governo e construir a memória do Presidente como o criador das leis trabalhistas. Todas as providências tomadas desde a Revolução de I930 envolvendo a questão social eram remetidas diretamente a Vargas. 
Em contrapartida, a oposição ao Estado Novo, agremiada na União Democrática Nacional, conscientes da importância atribuída pelos trabalhadores das leis sociais promulgadas por Vargas, tentou desvincular a imagem do Presidente aos benefícios que eles conquistaram com a legislação trabalhista. Carlos Lacerda, um dos principais líderes da UDN, em comício promovido pela União Nacional dos Estudantes (UNE), no Rio de Janeiro, discursou:

A demagogia do Estado Novo pensa haver conquistado o apoio do operariado com suas mistificações. Na verdade, a legislação trabalhista não é obra da ditadura, e sim de uma revolução liberal. E suprimiu todas as liberdades do operariado, reduzindo os sindicatos a simples máquina fascista. ${ }^{12}$

Carlos Lacerda defendeu que a legislação trabalhista não foi obra de Getúlio Vargas, mas sim de revolução liberal - a Revolução de I930. Criticou as conquistas trabalhistas ao discursar que elas suprimiram as liberdades do operariado e reduziram os sindicatos a manobras fascistas. Portanto, é percebido que seu discurso tenta desvincular as leis trabalhistas da personificação de Getúlio Vargas e menosprezá-las. Virgílio de Mello Franco, primeiro secretário-geral da UDN, segue a mesma posição de Carlos Lacerda. Em A Campanha da UDN, ele relata:

O povo, empobrecido continuadamente, foi também deseducado politicamente e, de maneira geral, mantido na ignorância, embrutecido pela miséria, envenenado pela propaganda. Dessa propaganda um exemplo é significativo: a que dava o sr. Vargas como "pai dos pobres" e criador da legislação brasileira do trabalho e da previdência social. Bem sabemos todos nós que ao cônsul Vargas e ao sistema que concretizava sua concepção do Estado é que devemos a transformação dos sindicatos de realidades vivas, órgãos livres de expressão democrática, em simples máquinas burocráticas, emanadas do Estado. Mas a propaganda aliviada à criação dos sindicatos o nome do homem que tirara aos operários a liberdade sindical e o direito de greve. (FRANCO, I946, p. 53-54).

Pierre Laborie propõe que "a memória intervém na fabricação da opinião pela influência das representações dominantes do passado. Por sua vez, a opinião tem papel

\footnotetext{
${ }^{12}$ Diário de Notícias. Rio de Janeiro, 8 de março de I945, p. 3.
} 
decisivo na validação social e na legitimação da memória ao dar credibilidade a seu discurso por meio de sua divulgação [...]”. (LABORIE, 2009, p. 80-8I). Laborie também aponta que a memória é o espaço em que um ponto de vista é articulado como a veracidade do fato, visto em:

faz-se da autenticidade, justamente atribuída à memória, uma espécie de garantia e de certeza de verdade. Por deslocamentos sucessivos, passa-se da memória portadora de uma verdade à memória lugar e expressão da verdade sobre o passado. O que era uma narrativa, uma representação ou um ponto de vista sobre o passado torna-se a história desse passado. (LABORIE, 2009, p. 92).

A partir das análises de Laborie e Pollak é possível compreender que os discursos de Lacerda e Franco narram a memória que eles possuem, a qual legitima suas opiniões sobre o governo varguista. Deve-se atentar que se tratava de opositores ao Estado Novo, em disputa pelo poder. Assim sendo os discursos de opiniões tinham por finalidade desconstruir o mito de "pai dos pobres" e propulsor dos direitos sociais construído em torno de Getúlio Vargas. No entanto, como já foi elucidado, houve batalha de memórias, em que a memória dos trabalhadores, que muito contribuiu os lugares de memória construídos pelo Estado Novo, legitimava as opiniões que discordavam das exposições de ideias da UDN.

A campanha do Brigadeiro foi intensamente acompanhada pela imprensa. Em São Paulo o jornal O Estado de São Paulo, e no Rio de Janeiro o Correio da Manhã, o Diário Carioca, o Diário de Notícias, reproduziam os discursos de Eduardo Gomes pelas cidades. Os Diários Associados, de Assis Chateaubriand, patrocinaram a campanha do candidato pelo país inteiro. Deveu-se à imprensa, a construção da imagem positiva do Brigadeiro e, sobretudo, o clima otimista em relação à vitória nas eleições.

Nas eleições de dois de dezembro de 1945, Eurico Gaspar Dutra foi vitorioso, obteve 55,39\% dos votos. Yeda Fiúza teve 9,7\%, Eduardo Gomes alcançou 35\%. As eleições, portanto, consagraram a vitória de Dutra, mas principalmente evidenciou a força política de Getúlio Vargas, uma vez que Vargas indicou à população que votassem em Dutra. A União Democrática Nacional conseguiu derrubar o Estado Novo, mas longe esteve de retirar o prestígio de Vargas. Sobre a perda das eleições, Virgílio de Mello Franco olhou com positividade os feitos de 1945. Segundo ele o fato de "ter demolido a ditadura foi um 
triunfo maravilhoso, senão milagroso" (FRANCO, 1946: V). No entanto, a derrota de Eduardo Gomes surpreendeu a todos correligionário da UDN.

Apesar de sua derrota nas urnas para Eurico Gaspar Dutra em dezembro de 1945, seu nome fora aclamado pelo país como herói nacionalista de índole inquestionável, como é possível perceber na narrativa de Virgílio de Mello Franco:

Depois de ter dado tudo quanto pode de si mesmo, tal como em I922, em 1930, em 1935 e em 1937, o homem de ação e de pensamento, o homem solitário, isto é, o homem livre, coerente com seu nobre passado, regressa imaculado ao convívio dos seus camaradas.[...] Mas o país que pensa, sente e anseia, percebe claramente que Eduardo Gomes foi, é e continuará sendo o homem das forças excepcionais. E porque está escrito que a sua força imensa ainda será empregada ao serviço do país, ninguém duvida do seu destino. (FRANCO, 1946, p. 82).

A citação acima evidencia que há exaltação ao passado de Eduardo Gomes. Assim, a memória influencia na opinião sobre o personagem no contexto das eleições de 1945. A construção da opinião baseou-se em atuações no movimento tenentista de 1922, na Revolução de 1930, no combate ao movimento comunista de 1935 e em seu afastamento do governo diante da ditadura estadonovista. Assim sendo, as opiniões sobre o personagem foram construídas através de reinterpretações do passado. Há, portanto, interação entre o vivido e o aprendido, o vivido e o transmitido, no dizer de Pollak (1989). Dessa forma, podese compreender que a legenda de herói, nacionalista, comprometido com a pátria e salvador dela, foram construídas tendo como fundamento a participação de Eduardo Gomes na vida pública do país e teve como finalidade a propaganda política para candidato a presidente da República em I945 e, posteriormente, em I950.

\section{Referências}

BENEVIDES, Maria Victoria. A UDN e o udenismo: ambiguidades do liberalismo brasileiro, I945-I965. Paz e Terra, I98I.

BENJAMIN, Walter. Paris, capitale du XIXe siècle. Paris: Editions du Cerf, I993: 478-479. Tradução: Silva, Edson Rosa da.

CARVALHO, José Murilo de. A formação das Almas - O Imaginário da República no Brasil. São Paulo: Companhia das Letras, 1990. 
DRUMMOND, José Augusto. O movimento tenentista: intervenção militar e conflito hierárquico (I922-1935). Rio de Janeiro: Graal, 1986.

DULCI, Otávio Soares. A UDN e o anti-populismo no Brasil. Editora UFMG/PROED, 1986.

FERREIRA, Jorge. "Quando os trabalhadores "querem": política e cidadania na transição democrática de 1945”. In: O imaginário trabalhista: getulismo, PTB e cultura política popular I945-I964. Editora Record, 2005.

FRANCO, Virgílio Alvim de Mello. A Campanha da UDN I944-1945. Zélio Valverde, I946.

GOMES, Ângela de Castro. A invenção do trabalhismo. São Paulo: Vértice, editora Revista dos Tribunais, 1988.

GOMES, Ângela Maria de Castro; D'ARAÚJO, Maria Celina Soares. Getulismo e trabalhismo: tensões e dimensões do Partido Trabalhista Brasileiro. Rio de Janeiro: Centro de Pesquisa e Documentação de História Contemporânea do Brasil, 1987.

HALBWACHS, Maurice. A memória coletiva. São Paulo: Ed. Centauro, 2006.

LABORIE, Pierre. "Memória e opinião." In: AZEVEDO, Cecilia; ROLLEMBERG, Denise; BICALHO, Maria Fernanda; KNAUSS, Paulo. Cultura Política, memória e historiografia. Rio de Janeiro: FGV Editora, 2009.

LANNA JÚNIOR, Mário Cléber Martins. Tenentismo e crises políticas na Primeira República. In: FERREIRA, Jorge. \& DELGADO, Lucília de Almeida Neves. O Brasil Republicano: volume I O tempo do liberalismo excludente. Rio de Janeiro, Editora Civilização Brasileira, 20I0.

NORA, Pierre. Entre memória e história: a problemática dos lugares. Projeto História. Revista do Programa de Estudos Pós-Graduados de História. e-ISSN 2176-2767; ISSN oIO2-4442, v. Io, 1993.

POLLAK, Michael. Memória e identidade social. Estudos históricos, v. 5, n. IO, p. 200-2I2,I992. . Memória, esquecimento, silêncio. Revista Estudos Históricos, v. 2, n. 3, p. 3-15, 1989.

SILVA, Hélio. 1922: sangue na areia de Copacabana. Civilização Brasileira, I97I.

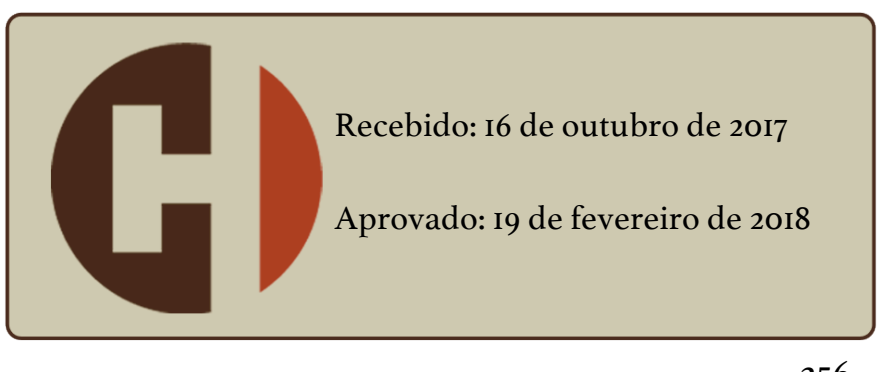

